\title{
EL CONSEJO DE ESTADO Y LA REFORMA CONSTITUCIONAL
}

POR

\author{
ÁNGEL SÁNCHEZ NAVARRO \\ Profesor Titular de Derecho Constitucional \\ Universidad Complutense de Madrid
}

\section{INTRODUCCIÓN}

El Consejo de Estado, «supremo órgano consultivo del Gobierno» de acuerdo con el artículo 107 de la Constitución de 1978, es un órgano normalmente discreto, de composición reducida, pero capaz de afrontar materias técnicamente muy complejas para elaborar dictámenes concisos y de gran calidad técnica. Y de hacerlo, además, con una rapidez que sin duda envidiarán otros muchos órganos e instituciones del Estado.

Como es natural, este órgano ha sido objeto de numerosos trabajos. Sin embargo, llama la atención el hecho de que la mayor parte de ellos proceden de autores profesionalmente vinculados a dicho órgano, o que desarrollan su labor en el ámbito del Derecho Administrativo ${ }^{1}$. Mientras que ha suscitado escaso - por no decir nulo- interés desde una perspectiva jurídico-constitucional, según pa-

${ }^{1}$ Entre ellos, cabe subrayar la abundancia de estudios debidos a Letrados del Consejo como José María Cordero Torres, Antonio Pérez-Tenessa, Eduardo García de Enterría, Javier Gálvez Montes, Ernesto García-Trevijano, Jorge Rodríguez-Zapata o David Blanquer Criado. Muchos de ellos, además, Profesores de Derecho Administrativo, como lo son también Ramón Parada, Luciano Parejo, Tomás Font, Ricardo Alonso García, Gerardo García Álvarez o Leopoldo Tolivar, entre otros. Igualmente, otros trabajos se deben a figuras como Luis Jordana de Pozas, Tomás De La Quadra o el malogrado Iñigo Cavero, quienes estuvieron vinculados al Consejo, durante más o menos tiempo, como Consejeros o Presidentes. 
rece confirmar un simple repaso de los principales Manuales y Tratados de Derecho Constitucional español.

Evidentemente, este dato resulta explicable desde muchos puntos de vista: al fin y al cabo, el Consejo de Estado francés se encuentra en el origen del Derecho Administrativo. Sin embargo, también subraya la escasa visibilidad de este órgano en nuestro régimen constitucional. Una circunstancia seguramente lógica, dada su tradicional inserción en el ámbito del Ejecutivo, pero que resulta significativa si consideramos la relevancia constitucional del Consejo de Estado.

Esa indiscutible relevancia constitucional se manifiesta, en primer lugar, por el dato formal de su inclusión en la mayor parte de los textos constitucionales españoles, desde 1808 hasta el actualmente vigente. Y se ha visto explícitamente confirmada por el Tribunal Constitucional al decir que «El Consejo de Estado, pese a la dicción literal del artículo 107 de la CE, que se refiere a él como supremo órgano consultivo del Gobierno, tiene en realidad el carácter de órgano del Estado con relevancia constitucional al servicio de la concepción del Estado que la propia Constitución establece» ${ }^{2}$.

En definitiva, esa escasa visibilidad no debe llamar a engaño. El Consejo de Estado lleva, literalmente, siglos desempeñando una labor más o menos callada, pero siempre eficaz. Una labor históricamente presidida por su consideración, desde su propio nombre, como "Consejo», vinculado primero al Rey, y luego al Gobierno $^{3}$. El ejercicio de esta función consultiva ha justificado su permanencia, e incluso su reconocimiento al máximo nivel normativo, por encima de las transformaciones políticas e institucionales que ha experimentado España.

Ahora bien: esas transformaciones, como no podría ser de otra forma, también han afectado a este órgano y a su función constitucional, según pone de manifiesto el período transcurrido desde la entrada en vigor de la Constitución, en 1978, hasta la reciente reforma operada por la Ley Orgánica 3/2004, de 28 de diciembre. La cual, como se tratará de argumentar, y al margen de otras innovaciones quizás más llamativas ha atribuido al Consejo unas competencias - especialmente, en materia de reforma constitucional - que le han otorgado un inusual protagonismo institucional y político, y podrían llegar a afectar significativamente a la propia noción de la función consultiva que la Constitución le encomienda.

2 SSTC 56/1990, FJ 37; y 204/1992, respectivamente. Las cursivas han sido añadidas.

3 «El Concejo del Príncipe es una congregación o aiuntamiento de personas escogidas para aconsejarle en todas las concurrencias de paz i de guerra... A este aiuntamiento muchos lo llaman Consejo, dándole el nombre del fin, por do se inventó» (Fadrique Furió Ceriol, El Concejo y Consejeros del Príncipe. Madrid, Tecnos, 1993 [1599], Capítulo primero, p. 15). 
En consecuencia, el trabajo pretende esbozar los perfiles constitucionales del Consejo de Estado, y de la función que nuestro ordenamiento le atribuye; para analizar, a continuación, la incidencia que sobre esa configuración puedan tener las modificaciones estructurales y competenciales introducidas por la citada Ley Orgánica, plasmadas por primera vez en el conocido «Informe sobre modificaciones de la Constitución española», aprobado por el Pleno del Consejo en su sesión de 16 de febrero de $2006^{4}$.

\section{LA CONFIGURACIÓN DEL CONSEJO DE ESTADO EN EL RÉGIMEN CONSTITUCIONAL}

\section{a) Antecedentes y modelos en el Derecho comparado}

A los efectos que aquí se persiguen, conviene aludir, siquiera sea muy brevemente, a los antecedentes históricos de un órgano tan peculiar como éste. Para lo cual, conviene recordar que, en sus orígenes, la actividad consultiva del Consejo adquiría, respecto de los Monarcas absolutos, un alcance universal que se proyectaba sobre todas las funciones de éstos, ya fuesen normativas, jurisdiccionales, ejecutivas, etc. Sin embargo, sucesivos procesos de decantación histórica vinieron a perfilar mucho más esa noción: la separación de poderes (especialmente, entre legislativo y ejecutivo), la diferenciación entre Consejos de Estado y Consejos de Ministros, la progresiva configuración de los Monarcas como poder moderador... Todo ello determina que los Consejos de Estado se reconduzcan a la condición de Consejeros del Poder Ejecutivo, y en particular del Gobierno. En algunos países (de hecho, en la mayoría de los que han conservado la institución hasta hoy: Francia e Italia, pero también Bélgica, Holanda, Luxemburgo, Colombia y otros), dicha condición se proyecta sobre un doble campo de actividad: una, la consultiva en sentido estricto, es previa en términos lógicos y cronológicos, y sigue siendo de estricto asesoramiento al Gobierno; la otra, posterior en los mismos términos, implica la asunción de ciertas funciones jurisdiccionales en materia de contencioso-administrativo ${ }^{5}$. Pero en España, don-

${ }^{4}$ Como es sabido, el Informe fue aprobado por mayoría, registrándose tres votos particulares a cargo de los Consejeros don Manuel Díez de Velasco Vallejo, don Luis Díez-Picazo y Ponce de León, y don José María Aznar López, el último de los cuales votó en contra.

5 Algo que, por más que suponga hoy día el modelo "generalizado» de Consejo de Estado, no deja de plantear dificultades, singularmente porque viene a «exportar» la interpretación excepcional de un principio hoy casi universal, como es el de la separación de poderes, que se hizo en Francia, y conforme al cual «juzgar a la administración es administrar». Ello explica, por ejemplo, que el 
de históricamente esta segunda dimensión desapareció hace ya un siglo, queda reducida a la primera ${ }^{6}$.

Por ello, aunque pueda resultar superfluo subrayar que el Consejo de Estado actual es muy distinto de las figuras que, con el mismo nombre, encontramos en la España de Carlos V, en el Estatuto de Bayona, o en textos constitucionales históricos (Cádiz, el francés del año VIII) o vigentes (Constitución italiana), no debe soslayarse que todos ellos presentan rasgos comunes. En efecto, todos ellos son Consejos (es más: «Consejos de Estado»). Todos aconsejan/asesoran al poder ejecutivo (ya se concrete éste en un Monarca absoluto, constitucional, parlamentario, o en un Gobierno). Y todos responden a "consultas» y emiten «dictámenes» (avis, pareri). En definitiva, como apuntara ya hace más de cuatrocientos años Fadrique Furió Ceriol, los «Consejos» del Príncipe eran "congregaciones o aiuntamientos de personas» dedicados a «aconsejarle en todas las concurrencias de paz y de guerra», y que adoptan «el nombre del fin por do se inventó». Así que, una misma denominación encubre un órgano con fuertes elementos comunes (colegiación, función de consejo, competencia universal), que han sido capaces de sobrevivir a una transformación absolutamente radical de los sistemas políticos en que actúan.

Sin embargo, una aproximación a los perfiles constitucionales actuales de la institución exige, obviamente, un grado de precisión mucho mayor. De ahí la utilidad de los estudios históricos y comparados, que resaltan lo común y lo cambiante. De los procedimientos de elaboración de los preceptos constitucionales y legislativos que arrojan luz sobre lo esencial y sobre lo contingente. De las vicisitudes derivadas de la inserción de esta noción, tan tradicional, en un siste-

Tribunal Europeo de Derechos Humanos, en su Sentencia de 28 de septiembre de 1995 (caso "Procola contra Luxemburgo») cuestionase, indirecta pero significativamente, la configuración del Consejo de Estado de ese país, que sigue el mismo modelo. En efecto, en el caso objeto de enjuiciamiento, cuatro de los cinco miembros del Tribunal que tuvieron que pronunciarse, en sede jurisdiccional, sobre la legalidad de un reglamento, habían contribuido a su elaboración con anterioridad, en el ámbito de su función consultiva. Lo cual suscitaba, a juicio — más que fundadodel Tribunal, serias dudas sobre la «imparcialidad estructural» del órgano jurisdiccional, y por tanto sobre su adecuación a los requisitos establecidos por el artículo 6 del Convenio de Roma.

${ }^{6}$ En efecto, cabe recordar que en nuestro país «la incorporación del Tribunal contenciosoadministrativo al Tribunal Supremo" se produjo con la Ley (Maura) de 5 de abril de 1904 y el subsiguiente Real Decreto de 8 de mayo, que crean la Sala homónima en el Alto Tribunal, quedando el Consejo de Estado configurado, hasta nuestros días, como un órgano exclusivamente consultivo. Luis Jordana de Pozas afirma, tajantemente, que «a partir de este período se extingue la influencia francesa sobre la organización y funciones del Consejo de Estado» («El Consejo de Estado español y las influencias francesas a lo largo de su evolución», en Estudios de Administración Local y General, Madrid, Instituto de Estudios de Administración Local, 1961, p. 86). 
ma político tan innovador. De las interpretaciones doctrinales y jurisprudenciales de la misma. Todo ello contribuye a identificar y esbozar algunos rasgos configuradores del Consejo de Estado, y de la función consultiva que se le atribuye, en el esquema constitucional español.

De este modo, cabe subrayar que la auctoritas de este órgano reside, al menos en parte, en su irrepetible $-\mathrm{y}$, ciertamente, discutible o, al menos, matizable- condición de «institución varias veces centenaria». Igualmente ilustrativa es la contemplación de la evolución histórica que ha conducido a la consolidación del Conseil d'État francés y del Consiglio di Stato italiano: ambos aportan elementos de interés, destacando el dato de que uno y otro, partiendo de esquemas y orígenes similares al nuestro, han conservado también su primera y característica función consultiva, insertándola sin embargo en una estructura y una configuración orgánica netamente distintas de las de su homónimo español.

En particular, cabe señalar a este respecto que el Consejo de Estado francés ha adoptado un perfil profesionalizado y autónomo, que ha contribuido a reforzar su auctoritas y la de sus miembros. Ello le ha permitido, pese a que la vigente Constitución de 1958 sólo recoja su función consultiva en el ejercicio de ciertas potestades normativas del Gobierno, mantener también su función jurisdiccional, en una dualidad funcional característica y que resulta, a los ojos de muchos, indisociable: «el Consejero del Gobierno se apoya sobre la jurisprudencia. El juez toma en consideración las opiniones del Consejero... De ahí resulta la mejor garantía posible de seguridad jurídica, beneficiosa a la vez para los poderes públicos y para los ciudadanos» ${ }^{7}$. Y que es, además, sumamente efectiva ya que «la función consultiva del Consejo... tiene la impronta que le da el ser ejercida por el máximo órgano de la jurisdicción contencioso-administrativa: sus dictámenes cumplen una importante función preventiva y su efecto es claramente superior al de una mera opinión» ${ }^{8}$.

7 Renaud Denoix de Saint Marc, «Préface», en J. Massot y T. Girardot, El Conseil d'État. Paris, La documentation française, 1999, p. 9. El mismo autor señala en otro lugar que «esta dualidad [funcional] corresponde a dos maneras complementarias de ejercer el control sobre la Administración: una es preventiva, la otra curativa. Las dos exigen la misma independencia, tan necesaria para el que aconseja como para el que juzga. Gracias a este doble papel, y no a pesar de él, el Consejo de Estado ha podido desarrollar el Derecho Público durante tantos años y someter al Ejecutivo al control del juez» (citado por J. A. Carrillo Donaire, quien habla de la "paradoja esquizoide de tener que asesorar y controlar al tiempo al poder ejecutivo»: «Consideraciones en torno al bicentenario del Consejo de Estado francés (1799-1999)", en RAP, núm. 153, 2000, pp. 527-528).

${ }^{8}$ Este mismo argumento fue utilizado históricamente en nuestro país para oponerse a la amputación de la función contencioso-administrativa, que según algún diputado decimonónico implicaría la muerte del Consejo. De ahí que algún autor se refiera a la evolución del Consejo 
En cuanto a Italia, su Consejo presenta también ciertos elementos similares: en particular, la misma dualidad funcional se aprecia con claridad en su definición constitucional como «órgano de consulta jurídico-administrativa y de tutela de la justicia en la Administración» (artículo 100). En todo caso, resulta obvio que el ámbito de la consulta es estrictamente el jurídico-administrativo, mientras que su dimensión jurisdiccional adquiere mucha más presencia, hasta el punto de llegar a cuestionar la configuración consultiva del Consejo. En efecto, este órgano, junto con los Tribunales Administrativos Regionales, se ha integrado en el marco, mucho más amplio, del denominado «complejo orgánico» de la «justicia administrativa». En consecuencia, el Consejo se ha convertido, como regla general, en órgano de apelación, y tiene un notable protagonismo en el «Consejo de Presidencia de la Justicia Administrativa» (complejo orgánico en cierta medida paralelo al Consejo Superior de la Magistratura de la jurisdicción ordinaria), el cual está presidido por el Presidente del Consejo de Estado?.

En todo caso, y como en Francia, es posiblemente esta función jurisdiccional y la consiguiente exigencia de independencia (garantizada por la ley, de acuerdo con el mandato constitucional expreso del artículo 100) la que ha determinado la "profesionalización» del órgano. Ello ha implicado la creación de una carrera profesional común con los Tribunales Administrativos Regionales y de un Cuerpo (la «Magistratura administrativa»), al que se accede, normalmente, mediante un concurso público de méritos entre candidatos que cumplan ciertos requisitos de formación jurídica y experiencia profesional, y cuya superación supone el nombramiento como Referendario (Letrado).

\section{b) La configuración constitucional y legal del Consejo de Estado}

Todos esos antecedentes y modelos comparados otorgan suficiente perspectiva para analizar la configuración del Consejo en nuestra España constitucional, que se aleja considerablemente de la de sus homólogos citados. A tal fin, resulta significativa la revisión de los debates que condujeron, primero, a su recepción en el artículo 107 de la Constitución; y, posteriormente, a la aprobación de la inicial Ley Orgánica 3/1980, de 22 de abril.

francés como «la muestra de lo que podía haber sido y no fue» su homónimo español (G. García Álvarez, «El fracaso en España del modelo francés de Consejo de Estado (1845-1904)», en Documentación Administrativa, núms. 244-245, 1996, pp. 90 y 91).

9 L. Parejo: «La función consultiva en Europa: los Consejos de Estado francés e italiano», en Documentación Administrativa, núm. 226, 1991, pp. 67-72. 
En cuanto al momento constituyente, puede recordarse en primer lugar la conocida opinión de Ramón Parada para quien, "paradójicamente... cuando nuestro Consejo de Estado atraviesa el momento más bajo de su existencia, es cuando resulta inmune a su supresión o reforma sustancial por haber sido constitucionalizado» en el artículo 107 de la Constitución. Tal "paradoja» se explica por cuanto "perdidas las características funcionales y orgánicas que históricamente determinaron su creación, las funciones de asesoramiento jurídico que le restaban podían ser ya fácilmente cubiertas por otra institución, como la Dirección General de lo Contencioso del Estado u otro cuerpo de funcionarios letrados». En consecuencia, «el Consejo pudo haber sido silenciado por la Constitución... e, incluso, suprimido por una simple Ley Ordinaria». Es más: «la lógica constitucional llevaba al silenciamiento del Consejo de Estado y a la derogación de la ley que venía rigiendo desde el régimen político anterior» ${ }^{10}$.

A pesar de lo cual, el mismo autor escribe que «el Consejo de Estado salvó su vida y aseguró su continuidad institucional porque las Constituyentes de 1978 lo citaron para exigir su dictamen preceptivo en el ejercicio de la delegación de materias de titularidad estatal a las Comunidades Autónomas (art. 153) y, sobre todo, porque, en función de lo dispuesto en el artículo 107, lo configuraron como supremo órgano consultivo del Gobierno, remitiendo a una Ley Orgánica la regulación de su composición y competencia» ${ }^{11}$.

De cualquier forma, y como probablemente era de esperar, ese reconocimiento constitucional no fue, ni mucho menos, indiscutido. En efecto, durante el iter constituyente se plantearon diversas opciones a este respecto (incluyendo, desde luego, la de su supresión), cuyo conocimiento constituye, sin duda, un primer dato que permitirá ilustrar el perfil constitucional del órgano y, especialmente, de su función consultiva.

Porque, como ya se ha apuntado, y a diferencia de lo que ocurre con sus homólogos francés e italiano, la significación constitucional del Consejo de Estado viene claramente dada en España por la de la única función que conserva, por expreso mandato constitucional: la consultiva, concretamente referida al Gobierno. Su naturaleza, objeto y alcance adquieren, pues, una relevancia constitucional indiscutible, como pone de manifiesto su presencia en el propio debate constituyente.

10 «El Consejo de Estado», en Documentación Administrativa, núm. 226, 1991, pp. 114 y 120-121. En cuanto a sus funciones originarias, este autor consideraba «imposibilitada la vuelta atrás por el principio de unidad judicial, que impedía atribuirle de nuevo funciones judiciales..., y por el principio democrático de plena responsabilidad del Gobierno en la función ejecutiva y ejercicio de la potestad reglamentaria, incondicionadas, en principio, por exigencias de dictámenes o consultas preceptivas y, menos aún vinculantes».

11 Ibidem. 
Así las cosas, el primer dato reseñable de este proceso es el de que, pese a la lógica constitucional señalada por R. Parada, el Consejo de Estado aparece, desde el primer momento, en el texto constitucional ${ }^{12}$. Y que lo hace, además, en términos prácticamente idénticos a los finalmente aprobados ${ }^{13}$. Es más: el examen del iter constituyente permite matizar la afirmación de que «la cuestión fundamental que se propuso [en el debate] fue la relativa a su permanencia en el texto constitucional ${ }^{14}$. Porque si, obviamente, ésa fue la cuestión fundamental desde el punto de vista lógico, lo cierto es que «el nudo central de la discusión» fue otro asunto, el relativo a la posición constitucional del Consejo ${ }^{15}$. Y, más concretamente, fue la definición del Consejo como «supremo órgano consultivo» exclusivamente referido al «Gobierno» la que provocó un mayor número de enmiendas, todas ellas en un sentido similar ${ }^{16}$, y que lograron un apoyo considerable, e incluso en algún momento mayoritario ${ }^{17}$.

En todo caso, un análisis detallado del debate muestra que el proceso constituyente no cuestionó frontalmente la concepción tradicional del Consejo de Estado. Antes al contrario, «la Constitución... no crea un nuevo Consejo de Estado, sino que protege su continuidad, su rango y sus funciones con la especial garantía jurídica que supone la consagración constitucional y la reserva de ley orgánica» ${ }^{18}$.

${ }^{12}$ Es más: Tomás de la Quadra-Salcedo afirma que su inclusión en el texto constitucional fue decidida «unánimemente» por los ponentes («El Consejo de Estado en un Estado Social y Democrático de Derecho", en AA.VV., Gobierno y Administración en la Constitución. Madrid, Instituto de Estudios Fiscales, 1988, vol. I, p. 213.

13 El artículo 106 del Anteproyecto (Boletín Oficial de las Cortes [BOC], núm. 44, de 5 de enero de 1978, p. 687) rezaba que «El Consejo de Estado es el supremo órgano consultivo del Gobierno. La ley regulará su composición y competencia». Las cursivas, que han sido añadidas, resaltan el único cambio respecto al texto definitivo, que las sustituyó por la referencia a "Una ley orgánica».

${ }^{14}$ F. Garrido Falla, «Artículo 107», en Comentarios a la Constitución. Madrid, Civitas, 1980, p. 1078.

15 T. de la Quadra-Salcedo, ob. cit., p. 229.

16 Con formulaciones y justificaciones muy similares, todas pretendían definir al Consejo como «supremo órgano consultivo del Gobierno y de la Administración» (Congreso, enmienda núm. 7); o «en asuntos [materias] de gobierno y administración» (Congreso, núms. 74 y 779; Senado, núms. 617 y 905).

${ }^{17} \mathrm{La}$ Comisión de Asuntos Constitucionales del Congreso aprobó, en efecto, la enmienda número 779 (vide nota anterior), que fue defendida por el Diputado Sr. Herrero Rodríguez de Miñón. Sin embargo, el Pleno de la Cámara volvió a la redacción inicial, al aprobar tres enmiendas idénticas de los Grupos Socialistas del Congreso, Socialistas de Cataluña y Comunista. En el Senado, el pacto entre las grandes formaciones mantuvo inalterado el texto.

${ }^{18}$ Ana Isabel Santamaría Dacal, «El Consejo de Estado», en J. Rodríguez-Arana Muñoz (Dir.) y M. ${ }^{a}$ Calvo Charro (Coord.), La Administración Pública Española. Madrid, INAP, 2002, p. 725. 
De esta manera, y según la interpretación que se hizo durante los debates, el constituyente acogió la atribución al mismo de la «función consultiva» que históricamente caracterizaba al Consejo. Por más que —seguramente en contraposición al antecedente de la Ley Orgánica del Estado- se reforzase su vinculación al Gobierno, en detrimento (más aparente que real) de su orientación estrictamente administrativa.

Ahora bien: es evidente que la somera definición constitucional del Consejo y la subsiguiente remisión a la Ley orgánica para regular su composición y competencias dejaba un amplio margen de apreciación al legislador a la hora de delimitar concretamente los perfiles de este órgano y de su función. De ahí la trascendencia del proceso que condujo a la aprobación de la Ley Orgánica 3/1980, de 22 de abril, del Consejo de Estado (LOCE), aún vigente.

Este proceso se inició con un Proyecto de Ley Orgánica que dejaba pocas dudas de su vocación absolutamente continuista ${ }^{19}$. Entre apelaciones a la Historia y al Derecho comparado (particularmente francés e italiano), su Exposición de motivos presentaba al «Alto Cuerpo... fundamentalmente [como] asesor del Gobierno y de la Administración Central», sin perjuicio de abrirlo incluso a las Comunidades Autónomas. Y, respecto de su contenido, se destaca la «continuidad sustancial» en cuanto a sus competencias y el mantenimiento de «su estructura tradicional». Sin embargo, y a diferencia de lo que ocurrió en el debate constituyente, en esta ocasión el modelo tradicional español del Consejo de Estado sí fue seriamente cuestionado. Muy minoritariamente, es verdad; pero no por ello de modo menos radical y coherente, provocando un esclarecedor debate sobre el sentido mismo del órgano, su carácter y la función que habría de desempeñar. Un debate que, curiosamente, apenas ha merecido atención doctrinal.

La discusión se suscitó en torno al artículo 2 del proyecto, según el cual «en el ejercicio de la función consultiva, el Consejo de Estado velará por la observancia de la Constitución y del Ordenamiento jurídico. También podrá valorar los aspectos de oportunidad y conveniencia cuando lo exija la índole del asunto o lo solicite expresamente la Autoridad consultante». Se concretaba de esta forma el contenido de la «función consultiva» encomendada por el constituyente, y que el Consejo habría de ejercer en relación con el listado de supuestos en que se le reconocía competencia, ya en Pleno (art. 21), ya en Comisión Permanente (art. 22); ya con carácter preceptivo, ya facultativo.

19 Boletín Oficial de las Cortes Generales [BOCG], Congreso de los Diputados, I Legislatura, Serie A, núm. 74-I, de 21 de septiembre de 1979. Todo el procedimiento se recoge en el volumen Consejo de Estado. Trabajos parlamentarios, editado por Francisco J. Gálvez Montes y publicado por las Cortes Generales en 1980. 
Pues bien: la redacción del precepto se reformó en algunos aspectos formales, pero no por ello menores (fundamentalmente, para ajustarla a la fórmula del artículo 9.1 CE: «la Constitución y el resto del Ordenamiento jurídico; y para permitir también esa valoración «de oportunidad y conveniencia» cuando lo exija «la mayor eficacia de la Administración en el cumplimiento de sus fines»). No obstante, la discusión se centró, sobre todo, en la fórmula de su segundo inciso, así como en el posible alcance y consecuencias del mismo.

Fue el Grupo Comunista el que, de forma más rotunda, criticó este aspecto: a su juicio, «la función del Consejo de Estado, por su propia naturaleza, debe limitarse a velar por la observancia de la Constitución y del Ordenamiento Jurídico, sin entrar en consideraciones de tipo político, para lo cual no es el órgano adecuado $»^{20}$. Pero también la Minoría Catalana solicitó la supresión de ese inciso, "por entender que la función de valorar la oportunidad y conveniencia de determinado asunto son aspectos de estricta consideración política en los que no puede interferirse el Consejo de Estado ni excusarse el Gobierno o la Administración en el dictamen de dicho organismo».

En el curso del debate, el ponente del Grupo Comunista, Josep Solé Barberá expuso que, para su Grupo, «la estricta misión del Consejo... dentro de nuestras instituciones políticas y administrativas» debía ceñirse a «una función consultiva sobre materias jurídicas y de Administración atendiendo a criterios de legalidad y buen funcionamiento objetivo de la Administración..., sin inmiscuirse para nada... en valoraciones de oportunidad y conveniencia que, prácticamente, serán siempre de carácter político, para cuya tarea existen otras instituciones y... [en particular] el Parlamento». La referencia a los modelos francés e italiano sirvió para resaltar que, en ambos casos, «aparece clara la delimitación de la materia sobre la que versa esta función consultiva y el tipo de análisis efectuado por el Consejo», de donde resulta su concepción "como un órgano consultivo del Gobierno en materia jurídica y... de Administración» que opera «atendiendo a criterios de legalidad y buen funcionamiento de la propia Administración $»^{21}$.

Por el contrario, a su juicio, el proyecto contenía «unos supuestos de posible intervención del Consejo de Estado que, a pesar de tratarse de un órgano puramente consultivo cuyos dictámenes no son, en principio, vinculantes para el Gobierno... abren la puerta a valoraciones políticas... de las que... entendemos

20 Enmienda número 18.

${ }^{21}$ Diario de Sesiones del Congreso de los Diputados [DSC], Pleno, I Legislatura, número 58, de 27 de diciembre de 1979, pp. 3949-3951 y 3955-3956. En términos similares se manifestó el Diputado de la Minoría Catalana Llibert Cuatrecasas (pp. 3954-3955). 
que [el Consejo de Estado]... debe quedar total y absolutamente marginad[o]..., muy especialmente porque esto invadiría funciones que corresponden, única y exclusivamente, al Parlamento».

En definitiva, «hablar de oportunidad, ... de conveniencia, es introducir criterios que, en auténtica juridicidad, no tienen contenido, o tienen un solo contenido, un criterio y un contenido de carácter político... que permite desviaciones de este concepto de juridicidad que nosotros defendemos». El Consejo precisa de «un criterio objetivo, es decir, si un proyecto de ley se ajusta o no a la Constitución; si un proyecto de ley, o un decreto o cualquier forma legislativa del Gobierno o de la Cámara se ajusta de manera estricta a nuestros principios jurídicos»; mientras que la vigilancia sobre la conveniencia o no de los actos del Gobierno «corresponde... exclusivamente a las Cortes». Es más: un Consejo de Estado «que cumpla la misión de asesorar al Gobierno... no podrá sustituir jamás en ninguna función de decisión ni en ninguna función de gobierno al propio Gobierno».

Coherentemente con esa noción estrictamente jurídica del Consejo (que justificó el voto en contra de la totalidad de la ley), el mismo Grupo se opuso frontalmente a la composición del órgano establecida por el texto. Según su criterio, la misma consagra «una dependencia total de los vocales y de los miembros del Consejo de Estado en relación con el Gobierno... dejando que quede en manos del Gobierno el nombramiento de dos terceras partes del Consejo", en flagrante "contradicción con aquello que nuestros vecinos... de Francia e Italia han establecido en sus propios organismos y formas de componer el Consejo de Estado».

Finalmente, todas estas enmiendas fueron rechazadas. No obstante lo cual, sus preocupaciones dejaron huella: la Ponencia llegó a «advertir» sobre «los inconvenientes de la posible politización del Alto Cuerpo Consultivo"; mientras que, en el debate plenario, el Diputado centrista Sr. Escartín Ipiens afirmó compartir "plenamente la preocupación de que el Consejo de Estado no es bueno que se politice», pese a lo cual no creía "que ni de [sus] antecedentes históricos, ni de la propia ley..., como tampoco de los criterios de valoración... de oportunidad y de conveniencia se tiene que deducir necesariamente una politización» del mismo. Es más: de tales criterios nunca podría deducirse «un criterio antijurídico, porque en tal caso tales decisiones no serían ajustadas al Derecho, serían nulas e impugnables». Pero sí permiten que entre en juego la "prudencia política como base de las decisiones de un Estado» ${ }^{22}$.

Por último, cabe mencionar un aspecto que, aunque parezca secundario, puede ser útil para entender el sentido institucional atribuido al Consejo por el

22 DSC, Pleno, I Legislatura, núm. 58, de 27 de diciembre de 1979, pp. 3953-3955. 
legislador, marcando además con toda nitidez una importante diferencia con los ejemplos francés e italiano. En efecto, en España no existe, como en esos otros modelos, una «carrera profesional» dentro del Consejo (una «magistratura» por utilizar la denominación italiana), que abarque desde el acceso como Letrado (auditeur, referendario) hasta la condición de Consejero de Estado: la única promoción formal es la que contempla el artículo 15.1 de la Ley Orgánica, según el cual «el ascenso a Letrado Mayor se llevará a cabo entre Letrados por riguroso orden de antigüedad en el Cuerpo». Pero no existe un cauce «automático», profesional, que permita a los Letrados acceder a la condición de miembros de pleno derecho del Pleno del Consejo ${ }^{23}$. De esta forma, en la composición del Consejo se aprecia con toda claridad «la existencia de dos niveles prácticamente incomunicados» (al margen, claro está, del personal subalterno o auxiliar): los Consejeros y los Letrados, que vienen a encarnar un componente "político o superior» y otro "técnico» ${ }^{24}$.

En todo caso, la propia Ley Orgánica interpretó el mandato de regular «la composición» del Consejo en un sentido amplio, incluyendo los principales elementos de su estructura. Lo cual «justifica la regulación esencial del status de los Letrados... en su calidad de componentes de las Secciones» ${ }^{25}$, atribuyéndoles, por lo demás, unas garantías de independencia notables ${ }^{26}$.

${ }^{23}$ Por más que el artículo 25.2 del Reglamento Orgánico del Consejo (R.D. 1674/1980, de 18 de julio) disponga (en términos muy próximos a los del anterior, de 1945) que, "cuando menos, dos de los Consejeros Permanentes han de proceder del Cuerpo de Letrados del Consejo de Estado".

${ }^{24}$ G. García Álvarez, La función constitucional del Consejo de Estado (Tesis doctoral, 1994), p. 182.

25 Áurea M. ${ }^{a}$ Roldán Martín, «La función consultiva de relevancia constitucional», en E. Álvarez Conde (Coord.) Administraciones Públicas y Constitución: reflexiones sobre el XX aniversario de la Constitución española de 1978. Madrid, INAP, 1998, p. 479. Razón por la cual la STC 99/1987, de 11 de junio, declaró «la inconstitucionalidad de un precepto legal [concretamente, un apartado de la Ley 30/1984, de Medidas de Reforma de la Función Pública] que integraba a los Letrados del Consejo en un Cuerpo funcionarial que también comprendía a Letrados de otros órganos de la Administración activa, considerando que los Letrados del Consejo se incardinan en la propia composición del Consejo de Estado" (Luis Cosculluela Montaner, Manual de Derecho Administrativo. Madrid, Civitas, 1997, 8. ${ }^{a}$ ed., p. 209).

${ }^{26}$ G. García Álvarez, La función constitucional..., ob. cit., pp. 80-81. Pese a lo cual, «su papel no deja de ser claramente subordinado» (Pablo Menéndez García y G. García Álvarez: Voz «Consejo de Estado", en Santiago Muñoz Machado [Dir.]: Diccionario de Derecho Administrativo, Madrid, Iustel, 2005, Tomo I, p. 612). 


\section{c) La evolución del Consejo de Estado en el régimen constitucional vigente}

Así pues, cuando el artículo 107 de la Constitución (reiterado por el 1.1 de la LOCE) atribuye a este órgano la condición de «supremo órgano consultivo del Gobierno", define el sentido institucional del mismo en el régimen constitucional español. Y lo hace en un doble aspecto: en sentido funcional, delimitando la esfera de su actividad, que queda circunscrita al ejercicio de la función consultiva; en sentido orgánico, presumiendo la existencia (o, al menos, admitiendo su posibilidad) de otros órganos dentro de esa misma esfera funcional.

A partir de ahí, y como no podía ser de otra manera, el Consejo de Estado - como tantas otras instituciones - ha debido adaptarse al nuevo marco constitucional (muy en particular, a la nueva organización territorial del Estado), que ha afectado a esos dos elementos definitorios. En lo orgánico, mediante la multiplicación y especialización de los órganos consultivos, tanto estatales como autonómicos, que han producido una auténtica «fragmentación» de la función consultiva. En lo funcional, primero mediante la concreción del contenido de esa función; y, en un momento posterior, mediante la reciente redefinición legal de ese contenido, que permite hablar de la «renovación» del mismo.

Porque, como ya se ha apuntado, el Consejo de Estado ha tenido siempre, desde sus orígenes históricos, una vocación de generalidad manifiesta ya en su misma denominación ${ }^{27}$. Una vocación que no ha perdido, pese al progresivo desgajamiento de sus originarias competencias políticas, administrativas y -al menos, en España- jurisdiccionales, que conllevan su acantonamiento en el ámbito estrictamente consultivo. Dentro del cual, sin embargo, la posibilidad de consulta al Consejo todavía se contempla hoy con una extraordinaria amplitud.

En efecto, desde 1980 la LOCE prescribía que «el Consejo... emitirá dictamen en cuantos asuntos sometan a su consulta el Gobierno o sus miembros, $o$ las Comunidades Autónomas a través de sus Presidentes» (artículo 20.1), y que «la consulta... será preceptiva cuando en ésta o en otras leyes así se establezca, y facultativa en los demás casos» (artículo 2.2) ${ }^{28}$.

27 Como escribiera en 1624 el Conde-Duque de Olivares, entre los Consejos «está el de Estado, que es el primero porque en él se tratan todas las materias universales de la Monarquía, que se constituye de todos los reinos referidos y que miran a la trabazón y unión de todo este sujeto que se compone dellos»: vid. Feliciano Barrios, El Consejo de Estado de la Monarquía española (1521-1812). Madrid, Consejo de Estado, 1984, p. 133, donde atribuye la cita a Elliot).

${ }^{28}$ Artículos 20.1 y 2.2 del texto inicial, convertidos en párrafos primero y segundo del artículo 2.2 tras la LO 3/2004 (que, además, ha suprimido el inciso en cursivas). Por otra parte, el Consejo «ha reconocido también legitimación para solicitar [su] dictamen... a otros órganos o entidades que gozan de una particular naturaleza por razón de las funciones que desempeñan, 
A partir de ahí, la misma Ley Orgánica delimita una esfera de consulta preceptiva materialmente muy amplia, a través de los prolijos listados de materias de sus artículos 21 y 22. Los cuales incluyen, además, cláusulas de remisión a otras disposiciones, de modo que deberá someterse al Consejo, en sus distintas formaciones, «todo asunto en que, por precepto expreso de una Ley, haya de consultarse al Consejo de Estado", ya sea "en Pleno", ya "en Comisión Permanente» (arts. 21.11 y 22.18) ${ }^{29}$. Y prevén también otra regla cuyo alcance es potencialmente ilimitado: el Consejo en Pleno «deberá ser consultado» sobre aquellos «asuntos de Estado a los que el Gobierno reconozca especial trascendencia o repercusión» (art. 21.10).

Añádase a ello que «el Consejo de Estado, sea en Pleno o en Comisión Permanente, puede ser oído en cualquier asunto en que, sin ser obligatoria la consulta, el Presidente del Gobierno o cualquier Ministro lo estime conveniente» (art. 24.1 LOCE 1980, 25.1 desde 2004). Y resulta así que, fuera del ámbito en que la solicitud de un dictamen (la consulta) venga expresamente requerida por alguna disposición expresa (constitucional, legal o reglamentaria), tal consulta será siempre facultativa para el Gobierno. El cual puede, pues, solicitar un informe o dictamen sobre cualquier asunto; mientras que dicho dictamen o informe, el acto consultivo mismo, es siempre un acto debido ${ }^{30}$. Queda así defi-

como es el caso del Banco de España y del Tribunal de Cuentas»: vid. Ernesto García Trevijano, «Sinopsis artículo 107», en el Portal de la Constitución española (www.congreso.es/constitucion).

${ }_{29}$ A este respecto, cabe hacer notar, en primer lugar, que los dictámenes del Consejo, ya sean de Pleno o de Comisión Permanente, "gozan de la misma naturaleza y efectos» (E. García Trevijano, en "Sinopsis artículo 107», cit.). A continuación, que la diferencia entre la atribución de competencias por una u otra vía no es baladí: como subraya Ricardo Alonso García, «lo que la LOCE permite es la incorporación por Ley ordinaria de nuevos supuestos de consulta preceptiva al Consejo de Estado, pero en ningún caso la alteración por Ley ordinaria de los enumerados en la LOCE; para ello sería necesaria una Ley igualmente orgánica» (Consejo de Estado y elaboración de reglamentos estatales y autonómicos. Madrid, Civitas, 1992, pp. 138-139). Y, finalmente, que el artículo 140 del Reglamento orgánico del Consejo (R.D. 1674/1980) dispone que «el Consejo de Estado publicará periódicamente en el Boletín Oficial del Estado la relación de las disposiciones que preceptúan la audiencia del Consejo, sea en pleno o en comisión permanente»: según la Resolución de la Presidencia del Consejo de Estado, de 21 de junio de 2005 (BOE del 28 del mismo mes), exigen la intervención preceptiva del Consejo no sólo los artículos 153.b de la Constitución y 21 y 22 de la LOCE; sino también otras dos Leyes Orgánicas; veinte Leyes estatales, otras seis autonómicas; cinco Reales Decretos Legislativos, y cerca de cuarenta disposiciones reglamentarias, en particular Decretos y Órdenes Ministeriales.

${ }^{30}$ De ahí «la incorrección lógica y dogmática que supone clasificar a los informes y, en general, a los actos consultivos, en preceptivos o facultativos. Estas dos categorías... sólo son de aplicación... [para] el órgano de la Administración activa», que podrá o no «solicitar un informe o dictamen». Una vez solicitado éste, su emisión "por parte del órgano consultivo será en todo caso 
nida, por consiguiente, una competencia que sigue siendo, como apunta la doctrina, «universal ${ }^{31} \mathrm{o}$ «de carácter general ${ }^{32}$.

En cualquier caso, esa vocación de generalidad en absoluto implica un monopolio de la función consultiva por parte del Consejo de Estado, el cual convive con otros «órganos consultivos» a los que «el ordenamiento... atribuye con carácter permanente la función de aconsejar, asesorar y suministrar elementos de juicio a los demás órganos de la Administración Pública, y de forma señalada a los órganos activos que manifiestan la voluntad resolutoria de la Administración» ${ }^{33}$.

La proliferación de tales órganos es una constante en los Estados contemporáneos, y también en España, desde hace ya mucho tiempo ${ }^{34}$. Sin embargo, en nuestro país este fenómeno se ha mostrado de forma particularmente clara durante el período de vigencia de la Constitución de 1978. En efecto, ésta ha venido a homologar muchas estructuras político-administrativas con las de otros países con tradiciones democráticas más antiguas, en los que tal evolución ha podido ser más paulatina. Y, además, ha producido una profunda descentralización del Estado, que también se ha visto reflejada en el ámbito consultivo.

Por otra parte, cabe señalar que esta proliferación orgánica parece comportar una simultánea «fragmentación» de la función consultiva. Porque si el Consejo de Estado asume una competencia definida con alcance universal o general, ésta resulta sin embargo indiscutiblemente afectada por la aparición de nuevos órganos consultivos que la ejercen en ámbitos más o menos concretos, pero cada vez más numerosos y diversos.

De este modo, cabe apuntar que este «desparramamiento» de lo consultivo, traducido en la multiplicación de órganos de este carácter, y la correlativa «fragmentación» del ejercicio de la función consultiva, se produce en un doble sen-

preceptiva» (T. Font i Llovet, "Órganos consultivos», en Revista de Administración Pública, núm. 108, 1985, pp. 69-70).

31 Gerardo García Álvarez, Función consultiva y procedimiento (régimen de los dictámenes del Consejo de Estado). Valencia, Tirant lo Blanch, 1997, p. 29.

32 Tomás Font i Llovet, «Órganos consultivos», cit., p. 80. Veinte años antes, Antonio Pérez(Tenessa) Hernández afirmaba también que «el Consejo... ejerce su función... en toda clase de asuntos de gobierno y administración, lo que lo distingue de los Consejos especiales» (El Consejo de Estado. Madrid, Centro de Formación y Perfeccionamiento de Funcionarios, 1965, p. 19).

33 T. Font i Llovet, «Órganos consultivos», ob. cit., p. 55.

${ }^{34}$ Hasta el punto de que Javier García Fernández habla, muy gráficamente, de «los nuevos fenómenos consultivos y de asesoramiento político que van desparramándose por el ordenamiento de cualquier Estado democrático» («Introducción» al número monográfico, coordinado por él mismo, sobre La función consultiva, en Documentación Administrativa, núm. 226, 1991, p. 5; cursivas añadidas). 
tido. Primero, en un plano «horizontal», esto es, en el ámbito de la organización de los poderes centrales del Estado ${ }^{35}$. Y a continuación, también en un plano "vertical», de distribución de competencias entre el Estado y las Comunidades Autónomas, las cuales, a raíz de la STC 204/1992, de 26 de noviembre, se han dotado en su práctica totalidad de órganos consultivos propios ${ }^{36}$.

\section{LA FUNCIÓN CONSULTIVA DEL CONSEJO DE ESTADO}

Cuanto hasta aquí se ha expuesto parece confirmar que, como se ha afirmado, «el elemento que caracteriza al propio concepto de órgano consultivo es la naturaleza de [su] actividad..., es decir, la actividad consultiva ${ }^{37}$. Y, por tanto, el examen de esta actividad adquiere plena relevancia al considerar la expresa caracterización del Consejo de Estado como «órgano consultivo» en el artículo 107 $\mathrm{CE}^{38}$. Una vez delimitado el contenido constitucional de la función consultiva atribuida al Consejo, será posible analizar la Ley Orgánica 3/2004, y su principal aplicación práctica, como es el «Informe sobre modificaciones de la Constitución española» de febrero de 2006.

Ahora bien: esta delimitación debe superar la dificultad que se deriva de la indefinición constitucional de dicha función, cuyo contenido no se precisa en nuestra Norma Fundamental. A pesar de lo cual, la doctrina concibe la «función consultiva» como aquella «que tienen encomendada los juristas», los cuales «la desarrollan en el seno de órganos independientes de cualquier poder», y "con-

35 Donde proliferan órganos de consulta muy diversos (unipersonales o colegiados; institucionalizados o ad hoc, representativos o no, técnicos o esencialmente políticos, etc.).

36 Recuérdese que, en dicha Sentencia, el Tribunal declara que «no sólo hay que reconocer la competencia de las Comunidades Autónomas para crear... órganos consultivos propios de las mismas características o semejantes funciones a las del Consejo de Estado sino, por la misma razón, estimar posible constitucionalmente la sustitución del informe preceptivo de este último por el de un órgano superior consultivo autonómico». Reforzando, eso sí, la función de garantía: «en donde o en tanto semejantes órganos consultivos autonómicos, dotados de las características de organización y funcionamiento que aseguren su independencia, objetividad y rigurosa cualificación técnica, no existan... las garantías procedimentales mencionadas exigen mantener la intervención preceptiva del Consejo de Estado, en tanto que órgano al servicio de la concepción global del Estado que la Constitución establece». Obsérvese que, con esta calificación de "global», el F.J. 5 «enriquece» la ya mencionada fórmula de la STC 56/1990 (literalmente reproducida en el F.J. 2), reforzando su sentido.

37 T. Font i Llovet, «Órganos consultivos», cit., p. 53.

38 Esta materia se desarrolla más ampliamente en A. Sánchez Navarro, «La función constitucional del Consejo de Estado tras su reforma por la Ley Orgánica 3/2004», en Revista de Administración Pública, núm. 169 (enero-abril 2006), pp. 353-382. 
sistente en responder autorizadamente a las consultas que se les formulen sobre el fundamento que en Derecho tengan pretensiones, proyectos o cuestiones sobre las que existan o puedan suscitarse dudas jurídicas» ${ }^{39}$.

Ello sitúa la juridicidad, el asesoramiento conforme a criterios jurídicos, como uno de los elementos presentes en la función consultiva stricto sensu. La cual precisa, según se ha dicho, que junto a este elemento - de naturaleza objetiva o funcional — confluyan otros dos: de una parte, el subjetivo u orgánico, que se concreta en un órgano que no actúa en virtud de su poder o potestas, sino de su auctoritas, la cual le otorga su independencia y su capacidad de influencia frente a los demás poderes. De otra, el institucional, que —en estrecha vinculación con el anterior- asegura la autonomía orgánica y funcional del órgano llamado a ejercerla.

En ese cuadro, la auctoritas o autoridad moral constituye el fundamento de la legitimidad de la intervención del Consejo, permitiéndole aparecer ayer junto al Rey, y hoy junto al Gobierno, pero sobre todo capaz de influir en su actividad, de "transfundir» cierta autoridad moral o legitimidad adicional a las decisiones en las que interviene. Y de hacerlo, simplemente, por la fuerza de convicción de sus argumentos, por el reconocimiento de su calidad, y no por la atribución jurídica de ninguna potestad.

Ahora bien: es claro que la auctoritas que proporciona el saber social e institucionalmente reconocido requiere un contexto de independencia, orgánica y funcional, que proteja al órgano frente a instrucciones o presiones externas, que puedan desvirtuarlo. Un contexto que, precisamente por alejarle de la participación directa en la elaboración de actos o disposiciones concretas, permite al Consejo de Estado, observarlos «desde una perspectiva general o de conjunto $»^{40}$.

En cuanto a la señalada «juridicidad», parece indiscutible que el ordenamiento español ofrece datos suficientes como para afirmar que, al igual que en otros sistemas, la función consultiva que ejerce el Consejo de Estado se caracteriza claramente como una función de naturaleza técnico-jurídica, que opera en el ámbito estrictamente administrativo.

Así se desprende, en primer lugar, de un iter constituyente que modificó la definición clásica del Consejo, pero en absoluto cuestionó su configuración tradicional y su orientación estrictamente técnico-jurídica, al servicio fundamentalmente del poder ejecutivo y de su ámbito funcional. Y, en segundo término, de la conocida fórmula del artículo 2.1 LOCE («en el ejercicio de la función consultiva el Consejo de Estado velará por la observancia de la Constitución

39 Granado Hijelmo, Ignacio: «Técnica legislativa y función consultiva», en Anuario Jurídico de la Rioja, núms. 6-7 (2000-2001), pp. 188 y 200 (cursivas añadidas).

40 Vid. A. I. Santamaría Dacal, «El Consejo de Estado», cit., pp. 735. 
$y$ del resto del ordenamiento jurídico»). Una fórmula que en su momento suscitó un importante debate precisamente por su novedad, ya que ni la anterior Ley de 1944 ni su Reglamento orgánico de desarrollo consideraron necesario precisar cuál era el contenido de esta función, más allá de la definición general del Consejo como «supremo órgano consultivo en materias de gobierno y administración» ${ }^{41}$. Y que sólo suscitó rechazo en algún sector ante la posibilidad de que el Consejo, habilitado para hacer valoraciones según criterios de «oportunidad y conveniencia», pudiera reconducirlos a criterios políticos.

La naturaleza propiamente jurídica de la función atribuida al Consejo resulta igualmente del análisis detallado de sus competencias, recogidas en los artículos 21 y 22 de la misma LOCE, y que — al menos, como veremos, hasta la última reforma - exigían una actuación sujeta a reglas jurídicas precisas.

Todo ello justifica la inequívoca opinión del Tribunal Constitucional, para el cual el Consejo es «un órgano dotado de independencia funcional para la tutela de la legalidad y del Estado de Derecho», que «se ha venido configurando históricamente como órgano consultivo de las Administraciones públicas» (STC 204/1992). Algo en lo que coincide con el propio Consejo de Estado, que afirma que «cuando se trata de elaborar una ley, el dictamen se ha de constreñir a la constitucionalidad del anteproyecto, a su coordinación con el resto del ordenamiento jurídico y a cuestiones formales o de técnica normativa. También puede valorar los aspectos de oportunidad y conveniencia cuando lo exija la índole del asunto, pero sin olvidar que es al legislador en última instancia, y al titular de la iniciativa legislativa en primer lugar, a quien corresponde ejercer la opción política de las medidas, y que la prudencia aconseja no aventurarse en juicios de oportunidad si no se pueden hacer con conocimiento de causa o razonablemente» ${ }^{42}$.

Asimismo, y al margen de la ya apuntada referencia al Derecho comparado, en nuestro ordenamiento los órganos consultivos autonómicos se caracterizan por ser «órganos que dictaminan en estrictos términos de legalidad», cuyos miembros son juristas y cuyos «informes y dictámenes se basa[n] en las reglas de interpretación y argumentación que conforman el método jurídico» ${ }^{43}$.

41 Artículo 1 de ambas normas. Aún más restrictiva era la definición del Consejo como «supremo cuerpo consultivo de la Administración» en el artículo 40.IV de la Ley Orgánica del Estado de 1967.

42 Dictamen núm 3.071/1996, de 4 de septiembre, recogido en Antonio Pérez-Tenessa, Compendio de la doctrina del Consejo de Estado. Madrid, Consejo de Estado-Boletín Oficial del Estado, 2003, pp. 23-25.

43 Vicente Garrido Mayol, "Veinticinco años de función consultiva», en Revista de Derecho Político, Madrid, UNED, núms. 58-59 (2003-2004), pp. 580, 583, 572, 575; y J. L. López González, «Los Consejos Consultivos autonómicos», en www.iustel.com, epígrafe 2.d). 
Y es precisamente esta caracterización de la función consultiva del Consejo la que explica que los constitucionalistas apenas se hayan ocupado del mismo, abandonando su estudio a los cultivadores del Derecho Administrativo. Como señalara ya hace medio siglo Eduardo García de Enterría, «basta examinar las listas de consultas preceptivas para concluir que la intervención del Consejo de Estado suele ordenarse primordialmente a garantizar el funcionamiento objetivo de la Administración por relación a otros poderes constitucionales..., o la objetividad de la actuación administrativa frente a los particulares..., o, más simplemente aún, la objetividad de la Administración frente a las leyes que limitan — precisamente - su actividad... Esto explica también la naturalidad con que el Consejo es capaz de convertirse en cualquier momento en órgano jurisdiccional, más o menos formalmente, y cohonestar tal función con la función propiamente de consulta. Esta caracterización, tan insospechada por la concepción clásica... a que estos órganos consultivos se deben, es una consecuencia funcional rigurosa del carácter estructural con que tales órganos se configuran ${ }^{44}$.

En un sentido similar, el actual Presidente del órgano, Francisco Rubio Llorente, afirma que el «objetivo primordial» de la función del Consejo «sigue siendo» el de «velar por la observancia de la Constitución y del resto del ordenamiento jurídico. Ese objetivo primordial no le impide hacer consideraciones de oportunidad y conveniencia... pero esa posibilidad, que ha de utilizarse con la circunspección de la que el Consejo ha hecho gala hasta el presente, no le convierte en órgano político». Por eso, «sólo como órgano del Derecho, como órgano jurídico, no representativo o politico, se hace necesaria su existencia. Un órgano que no dice el Derecho en el caso concreto, que no es órgano jurisdiccional, pero tampoco simplemente asesor. Que valora la acción del Gobierno y la Administración desde el punto de vista jurídico, para comunicar a quien ha de decidir el resultado de su valoración, que es producto del entendimiento, no de la voluntad ${ }^{45}$.

De cualquier forma, la observación de la actividad consultiva desempeñada por el Consejo permite resaltar la diversa relevancia de su intervención, y adquiere especial importancia cuando se pretende analizar los perfiles constitucionales de su función. En efecto, los dictámenes de este órgano se insertan en procedimientos distintos, y de diferente significación, lo que permite, por ejem-

44 "Aspectos de la Administración consultiva (Prólogo a la traducción española de Mooney)», en Revista de Administración Pública, núm. 24 (1957), cit, pp.183-184.

45 «Discurso pronunciado en el acto solemne de incorporación de don José María Aznar López como Consejero Nato con carácter vitalicio por su condición de ex Presidente del Gobierno", el día 21 de abril de 2005, recogido en la Memoria del año 2005 del Consejo de Estado, aprobada por el Pleno del mismo en sesión del día 21 de diciembre de 2006 (accesible en la página web del Consejo: www.consejo-estado.es), pp. 51-52; las cursivas han sido añadidas. 
plo, afirmar que «tiene[n] especial trascendencia cuando lo consultado... son proyectos de disposiciones generales, ya que éstas están llamadas a incardinarse en el ordenamiento jurídico, [por lo que] serán susceptibles de reiteradas aplicaciones y, por tanto, de generar efectos sobre toda la ciudadanía ${ }^{46}$. En definitiva, el dictamen sobre anteproyectos normativos tiene un alcance $-y$ una relevancia- distinta, y seguramente superior, en términos generales, al que tiene por objeto proyectos de actos concretos.

Ahora bien la significación de estas diferencias también depende del ámbito material en que se manifiestan. Porque el Consejo de Estado se define constitucionalmente como «supremo órgano consultivo del Gobierno», y éste desempeña su actividad en distintas esferas. En particular, la Constitución define, en su artículo 97, un ámbito que podríamos denominar "estrictamente ejecutivo», que engloba la dirección de la Administración civil y militar, la función ejecutiva y la potestad reglamentaria, y en el que opera un riguroso control jurídico externo, por lo que el Gobierno está sujeto a unos límites objetivos, plasmados en la ley, y cuya efectividad aseguran los órganos jurisdiccionales. En consecuencia, dentro de este ámbito la tarea del Consejo se centra en disposiciones reglamentarias, recursos u otras iniciativas de naturaleza estrictamente administrativa.

Sin embargo, el Gobierno puede actuar fuera de esa órbita objetivada. Y así, cuando ejerce su función de dirección política, muy particularmente mediante la iniciativa legislativa, los controles externos y a posteriori sólo operan, si acaso, en una medida mucho menor y con muchos matices. En ese ámbito, la responsabilidad del Gobierno se concreta en términos políticos, tanto «difusos» (ante la opinión pública) como «institucionalizados» (ante el Parlamento). En otras palabras, en los sistemas democráticos parlamentarios, ése es el ámbito que se reserva para que el Gobierno (respaldado por «su» mayoría, y dentro del marco constitucional) "dirija la política», «haga política», aplique su programa, defina sus prioridades. Aquí prevalece la dimensión política, las opciones políticas de fondo y, precisamente por ese contexto de «mayor politicidad" y «menor juridicidad», la experiencia histórica, tanto española como comparada, muestra que la intervención del Consejo de Estado puede resultar problemática. Al fin y al cabo, si la función consultiva consiste en «velar por la observancia de la Constitución y del resto del Ordenamiento jurídico", ante un anteproyecto de ley apenas queda otro parámetro jurídico que la Constitución y, en su caso, los plasmados en los Tratados e instrumentos internacionales, o en el Derecho Comunitario.

Pues bien: en este contexto objetivo y funcional, sobre este órgano y en el ejercicio de esta función, resulta especialmente llamativa la reforma operada por

46 I. Granado Hijelmo, «Técnica legislativa...», cit., p. 193. 
la Ley Orgánica 3/2004 $4^{47}$. Una reforma aprobada por una mayoría muy amplia y que, como hemos desarrollado ya extensamente en otro lugar, presenta diversos aspectos de interés, relativos a su composición, a su estructura interna, a su funcionamiento... Pero que afecta, sobre todo, a las competencias del Consejo, hasta el punto de producir una auténtica «renovación» de la función consultiva atribuida al mismo ${ }^{48}$.

\section{LA RENOVACIÓN DE LA FUNCIÓN CONSULTIVA DEL CONSEJO DE ESTADO EN LA LO 3/2004}

En efecto, de acuerdo con la Exposición de motivos de la Ley, la reforma persigue un triple objetivo, proyectándose sobre la composición del Consejo, su estructura y sus competencias. Sin embargo, el núcleo de la reforma viene dado por la innovación competencial y funcional, la cual exige una reforma estructural que no podría entenderse prescindiendo de aquélla.

Y ello a pesar de que sin duda alguna el más llamativo de los cambios sufridos por la LOCE consiste en la introducción de la figura de los «Consejeros natos de Estado con carácter vitalicio", que se atribuye a "quienes hayan desempeñado el cargo de Presidente del Gobierno» (artículo 8.1). Una modificación que, precisamente por su dimensión política, justificó que los parlamentarios de Izquierda Unida rechazasen la Ley, por estimarla «contraria a la esencia del Consejo de Estado», en tanto podría afectar a «su independencia». Algo que, con matices, podría decirse también de la reserva que la Ley ha introducido dentro del grupo de los diez Consejeros electivos, y conforme a la cual «dos [de ellos] deberán haber desempeñado el cargo de Presidente del Consejo Ejecutivo de Comunidad Autónoma por un período mínimo de ocho años. Su mandato será de ocho años» (art. 9.2 $)^{49}$.

${ }^{47}$ Ley Orgánica 3/2004, de 28 de diciembre, por la que se modifica la Ley Orgánica 3/1980, de 22 de abril, del Consejo de Estado (Boletín Oficial del Estado, núm. 313, de 29 de diciembre de 2004, pp. 42199 y ss.).

48 Vide supra, las notas números 1 y 39.

${ }^{49}$ Como es sabido, ambas previsiones han sido ya aplicadas: de una parte, los ex Presidentes José María Aznar y Leopoldo Calvo-Sotelo se incorporaron al Consejo el 1 de marzo de 2005 y el 25 de enero de 2007, respectivamente, si bien el primero de ellos, de acuerdo con lo dispuesto en el artículo 35 ROCE, manifestó al Presidente del Consejo su voluntad de suspender el ejercicio de su función apenas un año más tarde (junio de 2006). De otra, el ex Presidente de la Junta de Comunidades de Castilla-La Mancha entre 1983 y 2004, don José Bono Martínez, fue nombrado Consejero electivo en junio de 2006, aunque también parece confirmado que va a renunciar a este cargo. 
Más relevante ha resultado ser, como se verá más adelante, el segundo aspecto de la reforma, que se concreta en la creación de la Comisión de Estudios. Porque la noción de función consultiva es perfectamente compatible, en principio, con la atribución al Consejo de Estado de la capacidad de realizar "por sí o bajo su dirección... estudios, informes o memorias» (art. 2.3). Y, por tanto, nada hay que objetar a las reglas que tratan de adecuar la estructura del Consejo a ese nuevo cometido, creando una "Comisión de Estudios», previendo nuevos instrumentos técnicos al efecto, o articulando fórmulas de colaboración con otros organismos o instituciones.

Ahora bien: esa Comisión suscita algunas dudas derivadas de su peculiar régimen jurídico, que no la configura como «una Sección más..., sino como una estructura paralela a la Comisión Permanente». Ésta queda así excluida "como tal en el procedimiento de elaboración de los informes o estudios». Y además, «al situarse en el mismo plano que la Permanente, cada una en el ámbito de sus competencias, la preside el propio Presidente del Consejo, y no un Consejero" ${ }^{50}$.

Aún más discutible es el hecho de que esta Comisión no goce de las mismas garantías de permanencia que su modelo francés o las Secciones españolas, ya que «estará presidida por el Presidente del Consejo de Estado e integrada por dos Consejeros permanentes, dos natos y dos electivos, designados por el Pleno a propuesta del Presidente» para un período de dos años, «sin perjuicio de su posible renovación». Junto a ellos, se integran el Secretario General del Consejo, al menos un Letrado Mayor y los Letrados que se consideren necesarios, admitiéndose adicionalmente la posibilidad de recabar la participación «de funcionarios de otros cuerpos de la Administración».

Se configura así, en definitiva, una Comisión designada a propuesta del Presidente del Consejo (que en España, a diferencia de lo que ocurre en Francia e Italia, es «nombrado libremente» por el Consejo de Ministros: artículo 6.1 LOCE), y con un fuerte componente de Consejeros designados por períodos de 2 años, renovables a voluntad del Pleno. Una Comisión cuya tarea se ajusta a un procedimiento específico, ya que la preparación de los asuntos atribuidos a la misma corresponderá «a los Presidentes de los grupos de trabajo», dirigidos por el Presidente del Consejo o el miembro de la Comisión de Estudios «que aquel designe, oída la Comisión», y formados por Letrados y, en su caso, por aquellas otras personas, funcionarios o no, cuya intervención se estime necesaria (arts. 113.2 y 119 ROCE). Y, por tanto, un órgano peculiar y claramente dife-

50 Vid. Juan M. ${ }^{a}$ Bilbao Ubillos: «El informe del Consejo de Estado sobre la reforma de la Constitución", en Revista General de Derecho Constitucional (Iustel.com), núm. 1 (junio de 2006), pp. 2 a 5 y 8. 
renciado, tanto por su composición como por sus procedimientos, de los demás órganos del Consejo, lo cual, probablemente, tampoco tendría mayor relevancia externa de no ser por las nuevas atribuciones que la Ley ha conferido al Consejo, y más concretamente a esta Comisión.

Porque, en efecto, desde el punto de vista competencial, y en lo que más interesa desde el punto de vista de la configuración de la función consultiva encomendada al Consejo por el artículo $107 \mathrm{CE}$, el núcleo de la reforma radica en tres de las nuevas competencias atribuidas al Consejo: en primer lugar, la ya mencionada de realizar "por sí o bajo su dirección los estudios, informes o memorias que el Gobierno le solicite», o los que «juzgue oportuno para el mejor desempeño de sus funciones» (art. 2.3 LOCE); en segundo término, la de «ser consultado» preceptivamente respecto de «los Anteproyectos de reforma constitucional, cuando la propuesta no haya sido elaborada por el propio Consejo de Estado» (art. 21.1); y, finalmente y sobre todo, la de elaborar «las propuestas legislativas o de reforma constitucional que el Gobierno le encomiende» (art. 2.3).

La dimensión política de la reforma es indiscutible y explícita desde sus primeros pasos, que la vinculan principalmente al «proceso político de la reforma» constitucional, planteado desde el debate de investidura como uno de los objetivos del Gobierno para la VIII Legislatura (2004-2008). Sin embargo, y al margen de sus eventuales propósitos, la dificultad radica en su contenido objetivo. Porque ya se ha señalado que, en principio, la tarea de elaborar «estudios e informes» no parece en sí misma problemática. Pero la experiencia histórica no sólo española, sino también italiana o francesa, muestra que la competencia del Consejo para «dictaminar» los proyectos legislativos, más allá de su dimensión estrictamente técnicojurídica consistente en asesorar sobre su adecuación a la Constitución o a otras normas (fundamentalmente, comunitarias e internacionales) y sobre su incidencia en el resto del ordenamiento, suscita dificultades. Y ello pese a que siempre se limita al análisis y dictamen de iniciativas ajenas, formuladas en términos claros y precisos (anteproyectos), y a que, desde luego, y al menos en lo que a nosotros se nos alcanza, nunca se ha planteado en la concreta esfera de la reforma constitucional.

Pues bien: lo que la nueva redacción de la LOCE admite es otra cosa. Se trata de «elaborar las propuestas legislativas o de reforma constitucional que el Gobierno le encomiende» (art. 2.3). Una tarea en la que, ciertamente, habrá de atender a «los objetivos, criterios y límites» señalados por el Gobierno, pero que no es usual entre los órganos equiparables, de uno u otro modo, al Consejo ${ }^{51}$.

51 Aunque esta innovación parece haber «creado escuela» en el ámbito autonómico, según atestigua el informe aprobado por el Consejo Consultivo de Galicia el 27 de enero de 2006, en cumplimiento de un encargo formulado por el Gobierno de la Xunta, acerca de las posibilidades de reforma del Estatuto de esa Comunidad Autónoma. 
Porque ello implica, como ha subrayado la doctrina italiana, que «el Consejo... actúa como político...: interpreta intereses, adopta opciones, formula directricess ${ }^{52}$. Tanto más cuanto expresamente se admite que puede proyectarse sobre el ámbito, intrínseca y evidentemente político, de la reforma constitucional.

Resulta obvio que, en ese ámbito, las consideraciones técnico-jurídicas (que pueden ser, indiscutiblemente importantes) ocupan un lugar subordinado frente a las estrictamente políticas. En efecto, la Constitución sólo regula el procedimiento de reforma constitucional desde el momento en que éste se inicia formalmente, es decir, cuando se aprueba el proyecto de reforma o se formula la correspondiente proposición. Así pues, el Consejo difícilmente podría advertir al Gobierno de la inconstitucionalidad de un anteproyecto de reforma constitucional a menos que en el mismo se incluyesen previsiones procedimentales (por ejemplo, si se pretende seguir la vía del $167 \mathrm{CE}$ en una materia reservada al procedimiento agravado del 168). Y, una vez más, los reparos se incrementan si la actividad no se limita a la mera consulta sobre un anteproyecto ya elaborado, sino alcanza la posibilidad de que el propio órgano consultivo pueda preparar «anteproyectos de reforma constitucional».

Al margen de ello, esta cuestión conduce a otras, entre las que destacan las relativas al procedimiento previsto por la Ley (y su desarrollo reglamentario) para el ejercicio de esta actividad. La cual, como ya se ha apuntado, se desarrolla a través de un procedimiento basado en la nueva Comisión de Estudios y sus eventuales grupos de trabajo alternativo, configurándose pues un iter alternativo y muy distinto al que hasta ahora era usual, por no decir exclusivo, del Consejo.

Evidentemente, ambos procedimientos presentan algunos aspectos comunes, como la posibilidad de que los Consejeros formulen votos particulares «contra el acuerdo de la mayoría», que habrán de acompañar a la decisión. Pero, fuera de ahí, las «nuevas funciones» también comportan nuevas reglas, como plazos específicos o la posibilidad de que la Comisión de Estudios presente al Pleno, si lo estima oportuno, "propuestas que incluyan dos o más opciones. Las opciones que no resultaran aprobadas por el Pleno se acompañarán a la propuesta mayoritaria si obtienen un mínimo de siete votos, sin perjuicio del derecho de cada Consejero a formular un voto particular conforme al artículo 107 de este Reglamento..." (art. 103.4).

Y la especialización procedimental continúa. De este modo, los «estudios, informes o memorias» pueden ser «encargados por el Gobierno» o realizados por

52 Sabino CASSESE, «L'attività consultiva del Consiglio di Stato in materia di norme», en G. Paleologo (a cura di): I Consigli di Stato di Francia e d'Italia, Milano, Giuffrè, 1998, p. 95 (cursivas añadidas). 
iniciativa «del Presidente [del Consejo], oída la Comisión de Estudios» (artículo 13.5 LOCE). En ambos casos, la Comisión de Estudios «ordenará, dirigirá y supervisará» su realización y, «una vez conclusos, emitirá juicio acerca de su suficiencia y adecuación al encargo recibido" (artículo 23.1 LOCE). En este supuesto, la remisión del acuerdo del Consejo de Ministros que plantee la consulta, «firmada por el Ministro de la Presidencia», «indicará... si la remisión se hace al Pleno o a la Comisión de Estudios», entendiéndose que «a falta de previsión expresa... corresponde a esta última» y previéndose, si el órgano competente es el Pleno, la eventual devolución a la Comisión de los «estudios, informes o memorias desechados» por aquél (arts. 123.5 y 105.2 ROCE, respectivamente).

Por el contrario, "las propuestas legislativas o de reforma constitucional que el Gobierno encomiende al Consejo de Estado» serán elaboradas por la Comisión de Estudios, sometiéndolas en todo caso al Pleno (art. 23.2 LOCE). Un Pleno cuya intervención, además, se desdobla en dos momentos, el primero de los cuales se asemeja a un «debate de totalidad», por no decir "de toma en consideración». En efecto, «cada propuesta... será sometida a un debate inicial de conjunto, concluido el cual el Presidente fijará un plazo en que los Consejeros podrán presentar, por escrito, enmiendas concretas. Tras el análisis de las enmiendas por la Comisión de Estudios, ésta expondrá por escrito su posición y la ponencia que, en definitiva, adopte, se elevará al Pleno para su debate y decisión» (art. 103.3 ROCE).

Se produce así una evidente "parlamentarización» de un Pleno en cuya composición, como ya se ha apuntado, juega un importante papel el elemento político. Lo cual, aplicada a materias políticamente significativas y/o controvertidas, puede convertirlo en "primera instancia de debate político" acerca de cuestiones tan importantes como las anteriormente señaladas. Una instancia en la que la mayoría absoluta, establecida por el artículo 16.3 como regla general de funcionamiento del Consejo, se sustituye por la mayoría simple. Y en la que se admite la posibilidad de emitir «votos particulares» e, incluso, "propuestas alternativas» a las adoptadas por la mayoría del Consejo, siempre que reúnan en el Pleno el mínimo de siete votos.

Todo ello, adicionalmente, en el seno de un procedimiento presidido por el principio general de «reserva», conforme al cual todos los Consejeros, Letrados y el personal del Consejo «están obligados a guardar secreto sobre las propuestas y acuerdos adoptados mientras los asuntos no estén resueltos y, en todo tiempo, sobre las deliberaciones habidas, así como sobre los pareceres y votos emitidos» (art. 8.1 ROCE). Algo que puede ser impecable para una discusión sobre las vicisitudes de un contrato administrativo, pero resulta difícilmente justificable, e incluso concebible, cuando afecta a una "propuesta de reforma constitucional». 
Tanto más cuando, según el artículo 134.2 de su Reglamento, el Consejo no puede elaborar propuestas genéricas: «las propuestas legislativas y de reforma constitucional se formularán en textos normativos completos, pudiendo presentarse ante la Comisión de Estudios o el Pleno propuestas que incluyan una pluralidad de opciones». Y puede, incluso, «acompañar a las propuestas sus observaciones acerca de los objetivos, criterios y límites fijados por el Gobierno" a los que debe «atender» ex 2.3 LOCE.

Por otra parte, esa nueva capacidad de elaborar un «texto normativo completo» planteaba, claramente, un importante problema en orden a la actividad natural de este órgano, que es la de dictaminar iniciativas ajenas en el momento inmediatamente anterior al de convertirse en actos o disposiciones jurídicas. De ahí que el Gobierno, a instancias del propio Consejo, asumiese una solución consistente en excluir de la necesidad de dictamen final aquellas propuestas que hubiesen sido elaboradas por el propio Consejo ${ }^{53}$. Lo cual suscita nuevas inquietudes: ¿es posible retocar el texto preparado por el Consejo? Porque, si es así, ¿dónde quedaría la supremacía de este órgano, exigida por el artículo 107? Pero si no lo es - lo que justificaría la eliminación de una nueva revisión técnica, por superflua—, ¿¿ónde se ubicaría la responsabilidad, indiscutiblemente política?.

En definitiva, el problema es que, si las opciones políticas están claramente formuladas, las cuestiones son simplemente de redacción y precisión técnica. Pero, si no lo están, el problema adquiere, obviamente, una dimensión distinta que, a nuestro juicio, excede con mucho cualquier alcance que se quiera dar a la función consultiva que constitucionalmente se encomienda al Consejo. Y puede llevar a éste a ocupar un lugar distinto en el juego de los poderes, situándole en un lugar indefinido, que participa de las características de los Gabinetes políticos, de las Comisiones de expertos, de las Secretarías Generales Técnicas... y, desde luego, del Parlamento. Ejerciendo, pues, funciones $-\mathrm{y}$ albergando debates - cuya sede institucional es otra, y en esa misma medida «asumiendo» responsabilidades no jurídicas, sino de otro orden, de naturaleza claramente política. Responsabilidades que, desde luego, no le corresponden, para las que no está diseñado y que, en última instancia, pueden afectar gravemente a la auctoritas que constituye el fundamento último de su actividad ${ }^{54}$.

53 Artículo 21.1: «El Consejo de Estado en Pleno deberá ser consultado en los siguientes asuntos: $1 .^{\circ}$ Anteproyectos de reforma constitucional, cuando la propuesta no haya sido elaborada por el propio Consejo de Estado».

54 Recuérdese, en este sentido, las rotundas palabras del Presidente Rubio Llorente cuando afirmaba que «sólo como órgano del Derecho, como órgano jurídico, no representativo o político, se hace necesaria [la] existencia» del Consejo (vid. supra, nota núm. 386). 
Pues bien: las dudas anteriormente expuestas no desaparecen, ni mucho menos, con el examen del supuesto que ha inaugurado la nueva regulación, plasmado en el Informe sobre modificaciones de la Constitución española aprobado por el Consejo de Estado en febrero de 2006. Aunque hay que decir que, como también apuntaremos, seguramente las cosas podrían ser distintas si las circunstancias fueran diferentes.

\section{LA APLICACIÓN DE LAS NUEVAS FUNCIONES DEL CONSEJO DE ESTADO: EL INFORME SOBRE LA REFORMA CONSTITUCIONAL}

Como es sabido, la reforma de la Ley Orgánica del Consejo de Estado se planteó estrechamente vinculada al proceso intrínsecamente político de la reforma constitucional. A partir de ese dato, lo cierto es que la participación del Consejo en dicho proceso podía articularse de dos formas distintas: de una parte, elaborando, por encargo del Gobierno, una "propuesta de reforma constitucional». De otra, mediante un «estudio o informe»; algo que en principio respondería perfectamente a la orientación expresada en sede parlamentaria en diversas ocasiones significativas ${ }^{55}$.

Así las cosas, el Acuerdo del Consejo de Ministros de 4 de marzo de 2005 solicitó al Supremo Órgano Consultivo, en Pleno, «que informe sobre las modificaciones de la Constitución española que se contienen en el documento que se acompaña (...) en los términos y con los objetivos reflejados» en el mis$\mathrm{mo}^{56}$. Parece así clara la opción por la segunda de las vías señaladas, a pesar de algunos términos que podrían inducir a la confusión ${ }^{57}$.

55 Efectivamente, durante el debate de investidura el entonces candidato a la Presidencia del Gobierno habló de «un informe previo que... constituirá la base de[l] proyecto» de reforma. Poco después, ante la Comisión Constitucional del Congreso, también la Vicepresidenta primera aludiría a un «informe que sirva de apoyo al proceso político de la reforma».

56 Las citas, tanto a la "Consulta del Gobierno" como al texto del «Informe sobre modificaciones de la Constitución española» proceden del volumen coeditado por el propio Consejo y el Centro de Estudios Constitucionales, bajo la dirección de Francisco Rubio Llorente y José Álvarez Junco (El informe del Consejo de Estado sobre la reforma constitucional. Texto del informe y debates académicos. Madrid, 2006). Las cursivas, aquí como en las citas que siguen, y salvo que se indique otra cosa, han sido añadidas.

57 Así, por ejemplo, «el documento» que el Gobierno remitió al Consejo invoca expresamente ambas posibilidades en su tercer apartado («Procedimiento y plazo»), que no sólo cita íntegramente el primer párrafo del artículo 2.3 de la LOCE («El Consejo de Estado realizará... los estudios, informes o memorias que el Gobierno le solicite y elaborará las propuestas legislativas o de reforma 
Por todo ello, no resulta extraño que el Consejo dedique el apartado 3.1 de la primera parte de su texto («I. Introducción») a especificar la "Naturaleza del informe». Como allí se explica, la Ley «otorga al Gobierno dos vías diferentes para actuar», y éste "ha optado por la primera» de ellas, solicitando un informe y «sin encomendarle — como también habría podido hacer- la elaboración de una o varias propuestas de reforma constitucional, ${ }^{58}$. Se trata, como subraya el propio Informe, de una «opción... con seguridad meditada y... [con] un significado político que condiciona de manera decisiva la tarea encomendada al Consejo. No se le pide la redacción de textos que den forma jurídica a una reforma cuyo contenido está ya definido, sino un informe acerca de las modificaciones constitucionales que la consulta define sólo por relación a los objetivos que el Gobierno considera deseables».

Ahora bien, dicho eso, el Consejo estima que «estos objetivos pueden ser entendidos de distintos modos». Y entre todos ellos, escoge aquél en el que «el Informe debe hacer el análisis crítico de las diversas posibilidades, para ofrecerlas como alternativas posibles a partir de las cuales cabe elaborar el proyecto de reforma constitucional». Lo cual no impide la propuesta de textos concretos: en efecto, «la naturaleza del trabajo que se le encomienda ha llevado al Consejo... a incluir en el Informe redacciones posibles de los preceptos constitucionales en los que habría de plasmarse la reforma, o cuya modificación resultaría indispensable como consecuencia de ésta», por más que tales «redacciones se ofrecen siempre... a efectos indicativos: para ilustrar el razonamiento y no, en modo alguno, como propuesta de textos para ser incorporados a un proyecto de reforma ya concluso». Al fin y al cabo, "una propuesta de ese género [no] es propia de un informe, ni hubiera sido posible formularla sin desbordar el marco establecido por el Gobierno".

De esta forma, y en justa correspondencia con el impreciso alcance de una consulta que solicitaba un informe a la vez que invocaba expresamente los "preceptos legales» relativos a la «elaboración de propuestas», el Consejo afirma que, de acuerdo con la opción gubernamental, lo que hace es elaborar un «in-

constitucional que el Gobierno le encomiende»), sino que recuerda también el párrafo siguiente («en la elaboración de las propuestas legislativas o de reforma constitucional [el Consejo] atenderá los objetivos, criterios y límites de la reforma constitucional señalados por el Gobierno, y podrá hacer también las estimaciones que estime pertinentes acerca de ellos»), para afirmar que "con apoyo en estos preceptos legales, el Gobierno solicita del Alto órgano consultivo que emita, antes de finalizar 2005, un informe sobre la reforma propuesta... sin perjuicio de que pueda abordar aquellos otros aspectos que, por estar relacionados con ellas, sea conveniente tener en cuenta para completarlas o mejorar su calidad técnica».

58 Informe..., cit., pp. 58 y 59 (cursivas en el original). 
forme». Pero, casi simultáneamente, justifica la inclusión en el mismo de «redacciones posibles de los preceptos constitucionales en lo que habría de plasmarse la reforma», por más que matice que ello se hace a efectos meramente «indicativos».

En cuanto al iter seguido, la elaboración del Informe se encomendó, según establece la Ley, a la Comisión de Estudios. Una Comisión que había sido constituida el 10 de febrero de 2005, quedando integrada - a propuesta del Presidente, aprobada por el Pleno- por «los Consejeros Permanentes don Landelino Lavilla Alsina y don Miguel Rodríguez-Piñero y Bravo-Ferrer, los Consejeros Natos don Carlos Carnicer Díez y don Joaquín de Fuentes Bardají y los Consejeros Electivos don Rafael Gómez-Ferrer Morant y don Pedro Cruz Villalón», junto al Presidente y el Secretario General ${ }^{59}$.

Siempre según la misma Memoria, el 9 de marzo se constituyeron dentro de esta Comisión «cuatro Grupos de Trabajo, uno por cada tema... La presidencia de dos de estos grupos ("sucesión a la Corona" y "Comunidades Autónomas") fue asumida por el Presidente. Los dos restantes fueron presididos por los Consejeros señores Lavilla Alsina ("Senado") y Rodríguez-Piñero y Bravo-Ferrer ("Integración europea”)». Añádase a ello que, según escribe el Presidente Rubio, "yo... preparé también el borrador de la Introducción y del Capítulo final sobre el procedimiento ${ }^{60}$, y el resultado es un procedimiento marcado, al margen de su resultado concreto en uno u otro caso, por un predominio presidencial probablemente desmesurado (y peligroso, en tanto el Presidente es «nombrado libremente por Real Decreto acordado en Consejo de Ministros»: artículo 6.1 LOCE). Una circunstancia que refuerza, sin duda, el contraste entre el Consejo español y sus homónimos de otros países.

Pasando al plano de los contenidos es claro que, como observa el Consejo, la consulta sólo define las modificaciones constitucionales objeto del informe «por relación a los objetivos que el Gobierno considera deseables». Lo que supone reconocer, ab initio, una absoluta indefinición de medios. Y la elección de los medios más adecuados para lograr unos fines puede tener claras implicaciones políticas, y no sólo técnicas.

59 Memoria del año 2005, cit., pp. 7 y 87.

${ }^{60}$ «Presentación» al Informe..., cit., pp. 21-22, y Memoria, p. 31. J. M. Bilbao Ubillos aporta el dato adicional de que «se discutió, y mucho, sobre la conveniencia de incluir en el Informe la reflexión en torno al procedimiento de reforma. A pesar de algunas objeciones y de la premura con que se había planteado, se impuso finalmente la tesis de que podría resultar sumamente útil el análisis de una cuestión crucial que suscita en la doctrina no pocas dudas» («El informe...", cit., pp. 12 y 15 ). 
Ciertamente, el Gobierno expresa en su consulta una serie de criterios, muy genéricos («que los cambios... respondan a demandas consistentes y... busquen resolver problemas o insuficiencias ampliamente reconocidas»; «que sean limitados y prudentes», que generen amplio consenso), a los que se añade, "como no puede ser de otro modo", la "condición imprescindible [de] que las reformas se lleven a cabo respetando escrupulosamente los mecanismos establecidos en la Constitución» ${ }^{61}$.

Se trata, como es obvio, de una serie de criterios muy genéricos, a los que ha de añadirse la opción gubernamental por una reforma restringida, circunscrita a aquellos cambios «sobre cuya oportunidad y necesidad exista una muy amplia coincidencia». Pero que han de completarse también con el expreso reconocimiento de que, en su tarea, el Consejo puede «abordar aquellos otros aspectos que, por estar relacionados con [tales cuestiones], sea conveniente tener en cuenta para completarlas o mejorar su calidad técnica».

Por ello, la apreciación del alcance de la consulta exige considerar detalladamente la formulación de cada una de las modificaciones sometidas a informe. Y así, por ejemplo, podría considerarse que tienen un calado esencialmente técnico - sin perjuicio de reconocer que pueden suscitar importantes cuestiones políticas - la solicitud de que el Consejo «se pronuncie acerca del modo de eliminar la preferencia del varón en el acceso al trono... salvaguardando expresamente los derechos del actual Príncipe de Asturias», así como la relativa al «modo de plasmar la manifiesta voluntad del pueblo español de participar, junto con las democracias europeas, en el proceso de construcción de la Unión».

Sin embargo, es mucho más difícil concebir en términos estrictamente técnicos la totalidad del tercer punto, que comprende «1. Qué artículo o artículos de la Constitución son los más idóneos para llevar a cabo esa mención expresa e individualizada de las Comunidades Autónomas y las dos Ciudades Autónomas. 2. Qué criterio o criterios considera el Consejo de Estado más adecuados para ordenar su enumeración. 3. Las eventuales consecuencias jurídicas que de la mención expresa de las Comunidades Autónomas... se pudieran derivar en relación con otros preceptos constitucionales». Cuestiones cuya complejidad e implicaciones, profundamente políticas, a nadie se le escapan. Tampoco, por supuesto, al Consejo de Estado, el cual, partiendo de que con esta modificación el Gobierno pretende «superar la apertura inicial del modelo de descentralización política establecido por el constituyente», considera que ello "autoriza, y aun obliga, a incluir en este Informe una reflexión sobre la apertura que se mantiene, a fin

${ }^{61}$ «Consulta...», cit., pp. 33-34. 
de sugerir, en su caso, las medidas necesarias para completar y perfeccionar técnicamente la reforma proyectada " ${ }^{62}$.

En consecuencia, como reconoce el propio Presidente Rubio Llorente, éste es «el capítulo del Informe en el que [las] consideraciones complementarias se llevan más lejos». Porque "la Comisión de Estudios, primero, y el Pleno del Consejo, después, han entendido que éste era, como proponía el Ponente [que, dicho sea de paso, era el propio Presidente], el lugar adecuado para incorporar, siquiera en esbozo, una reflexión general sobre nuestro peculiar modelo de organización territorial ${ }^{63}$. Desbordando, con toda evidencia pero razonadamente, los límites de una propuesta que en el discurso de investidura se presentó como una reforma "concreta y limitada de la Constitución», aparentemente modesta y casi simbólica.

De cualquier forma, probablemente la cuestión más problemática, prima facie, sea la cuarta, donde se pide al Consejo, ni más ni menos, el diseño de un modelo parlamentario alternativo, conforme a las siguientes cuestiones: «1. Las funciones que debe ejercer el Senado como Cámara de representación territorial y, en particular, el ámbito material y el grado de participación en el ejercicio de la potestad legislativa, las tareas que le correspondería desempeñar como espacio de concertación y cooperación de las Comunidades Autónomas entre sí y con el Estado, y las atribuciones relacionadas con otros órganos constitucionales. 2. La composición más adecuada para ejercer esas funciones y expresar la representación de los intereses territoriales, así como su articulación efectiva. 3. La posición institucional del Senado en el seno de las Cortes Generales en el ejercicio de sus funciones como Cámara de representación territorial». Y, finalmente, la 4. «Las consecuencias sistemáticas que comportaría en el conjunto de la estructura constitucional la adopción del correspondiente modelo de configuración del Senado» ${ }^{64}$.

En definitiva, esta primera experiencia viene a confirmar la singularidad de las nuevas funciones atribuidas al Consejo por la Ley Orgánica 3/2004, apuntando algunas de sus posibles repercusiones en el funcionamiento del órgano. En particular, y desde el punto de vista meramente procedimental, cabe subrayar la evidente e indiscutible quiebra del principio de «reserva» que preside todo el funcionamiento del Consejo, debido a la publicación íntegra, por diversos medios de comunicación, del Proyecto de Informe elaborado por la Comisión de Estudios, antes de su examen plenario el día 16 de febrero de 2006. Evidentemente, el efecto de una filtración como ésta, que seguramente resulte casi inevitable en

\footnotetext{
${ }^{62}$ Informe..., cit., pp. 127 a 129 (cursivas en el original).

63 «Presentación» al citado Informe..., pp. 22 y 23 (cursivas añadidas).

${ }^{64}$ Obviamente, las cursivas han sido también añadidas.
} 
un asunto de tal envergadura, no puede precisarse, pero resulta obvio que fue capaz de desencadenar un intenso debate social y político previo a su examen final en el Pleno del órgano.

$\mathrm{Al}$ margen de ello, la consecuencia más importante de esta experiencia ha resultado ser la, por otra parte previsible, y seguramente inevitable ubicación del Informe del Consejo en el centro del debate político, y los consiguientes intentos de «utilización» política y partidista del mismo. Intentos que, muy probablemente, han contribuido a «neutralizar» la más que estimable labor desarrollada por el Alto órgano consultivo. Porque, en efecto, muchas de sus propuestas, e incluso su planteamiento general, parecen haber sido acogidos fríamente por el Gobierno que encargó el Informe, mientras que han sido reivindicados por una oposición que ha creído encontrar en él la confirmación de algunas de sus tesis políticas sobre los problemas de articulación del Estado autonómico ${ }^{65}$.

Tal consecuencia parece inherente a la significación misma del procedimiento introducido en la Ley Orgánica del Consejo de Estado por la reforma de 2004, en tanto tenga por objeto cualquier materia mínimamente relevante y controvertida desde una perspectiva política. Sin embargo, también debe subrayarse que la puesta en marcha de las nuevas competencias del Consejo se ha producido en las más difíciles circunstancias concebibles, al recaer sobre una cuestión de la máxima dimensión política imaginable, como es la elaboración de una propuesta de reforma constitucional, cuyos límites además no estaban precisamente definidos, y todo ello en un contexto política y jurídicamente complejo. Pero es de esperar que ello no siempre sea así. Sirva, como elemento de contraste, el segundo Informe solicitado por el Gobierno al Consejo de Estado, acerca de "las competencias de las diversas Administraciones territoriales y órganos de la Administración General del Estado en materia de protección de hábitats y especies marinas y de declaración y gestión de áreas marinas protegidas». Un Informe aprobado por la Comisión de Estudios del Consejo el 19 de julio de 2006, y que presenta, desde luego, perfiles muy distintos, mucho más técnicos y, por tanto, mucho menos problemáticos por cuanto más ajustados a la configuración tradicional de la función consultiva.

${ }^{65}$ A pesar de lo cual, el Informe registró el único voto en contra del ex Presidente Aznar, que a pesar de reconocer en su voto particular que compartía "en altísima medida» la "orientación general y contenidos concretos» del texto, justificó su posición por una «discrepancia fundamental [que] no afecta a este Documento, con muchos de cuyos aspectos» reiteraba su "coincidencia general», sino "a la iniciativa a la que responde», ya que a su juicio «el contexto político no favorece el sosiego, ni estimula el acuerdo, necesario para una operación tan importante como es la de reformar la Constitución de todos» (recogido en El informe..., cit. pp. 259-266). 


\title{
Sumary
}

I. Introduction. II. The configuration of the Council of State in the constitutional régime. a) Antecedents and models in the Comparative Law. b) The constitutional and legal configuration of the Council of State. c) The evolution of the Council of State in the effective constitutional régime. III. The advisory function of the Council of State. IV. The renovation of the advisory function of the Council of State in the Organic Act 3/2004. V. The application of the new functions of the Council of State: the Report on the constitutional reform.

\section{Resumen}

El Consejo de Estado ha sido tradicionalmente estudiado por la doctrina administrativista, dada su inserción en el ámbito del Ejecutivo y su trascendencia en el desarrollo del Derecho Administrativo. Sin embargo, ello no justifica el olvido por parte de los constitucionalistas de este órgano, definido como «supremo órgano consultivo del Gobierno» en el artículo $107 \mathrm{CE}$. En consecuencia, se pretende aquí delimitar los perfiles constitucionales del Consejo y de la función que la Constitución le atribuye, sin precisar su contenido. Ello resulta especialmente relevante tras la reforma del Consejo mediante la Ley Orgánica 3/2004, que ha modificado su composición, su estructura interna y sus funciones, al hilo de una propuesta de reforma constitucional que reservó al Consejo un papel significativo, concretado en el «Informe sobre modificaciones de la Constitución española». Informe al que lógicamente se presta especial atención en lo que atañe a sus aspectos procedimentales y a su impacto en el sistema constitucional español.

\begin{abstract}
The Council of State has been traditionally considered as an administrative institution, given its position within the executive sphere and its relevance in the birth and development of that particular legal branch. But all those reasons cannot lead us to ignore that this organ is expressly defined as the «supreme consultative body of the Government» by the Spanish Constitution. Thus, this pages try to deepen in the constitutional profiles of this body and its function. A particularly important issue after the recent reform produced in the legal regime of this body by the Organic Act 3/2004, of December the 28th, which modifies its composition, its internal structure and its powers, with the purpose of making it possible for it to participate in the procedure for constitutional reform. The result of this participation is a Report on reforms of the Spanish Constitution, which of course receives parti-
\end{abstract}


cular attention, with respect to its procedural features and its possible impact on the Spanish constitutional system.

Palabras clave

Consejo de Estado, Función consultiva, Ley Orgánica 3/2004,Reforma constitucional

\section{Key words}

Council of State, Consultative function, Organic Act 3/2004, Constitutional reform 